\title{
Nylon-6/rubber blends: 6. Notched tensile impact testing of nylon-6/(ethylene- propylene rubber) blends
}

\author{
K. Dijkstra*, J. ter Laak and R. J. Gaymans $\dagger$ \\ University of Twente, PO Box 217, 7500 AE Enschede, The Netherlands \\ (Received 11 March 1993)
}

\begin{abstract}
The deformation and fracture behaviour of nylon-6/EPR (ethylene-propylene rubber) blends is studied as a function of strain rate and rubber content. Therefore, tensile experiments are conducted on notched specimens over a broad range of draw speeds (including strain rates as encountered in normal tensile tests and in impact tests). The blends with a high rubber content show super-tough behaviour at low and high speeds. In the intermediate-speed regime the fracture energy reaches a minimum (with a level comparable with that of unmodified nylon). The blends with a low rubber content show a transition from tough to brittle behaviour with increasing strain rate. The sudden rise in fracture energy with rising strain rate is believed to be caused by a transition from isothermal to adiabatic deformation. In the adiabatic regime the rise in temperature is high enough to melt the material around the crack tip. This thermal blunting mechanism causes crack propagation to be stable at high strain rates. This mechanism is affirmed by scanning electron microscope studies of the deformation zone.
\end{abstract}

(Keywords: nylon-rubber blend; impact behaviour; strain-rate effects)

\section{INTRODUCTION}

A subject that has been treated extensively in the literature is the temperature dependence of the impact behaviour of polymers and polymer blends For nylon-6 and nylon-6/rubber blends, an extensive study of the impact behaviour versus test temperature was made by Borggreve et al. ${ }^{1-4}$, who varied blend morphology (rubber concentration and rubber particle size) and rubber properties (mechanical properties and adhesion between rubber and matrix). More recently, the influence of particle size in nylon-6/EPR (ethylene-propylene rubber) blends was studied by Oostenbrink et al. ${ }^{5}$ and by Oshinski and coworkers ${ }^{6}$.

One of the most important conclusions from this work is that the temperature where the fracture type changes from brittle to tough behaviour (the $T_{\mathrm{BT}}$ ) appears to be a function of the average thickness of the ligament between two particles (the interparticle distance or $I D$ ). This was first proposed by $\mathrm{Wu}^{7,8}$ and confirmed by Borggreve $^{1}$. Wu derived a relation between the rubber content $\varphi_{\mathrm{r}}$, rubber particle size $d$ and $I D$, based on a cubic array of particles:

$$
I D=d\left[\left(\frac{\pi}{6 \varphi_{\mathrm{r}}}\right)^{1 / 3}-1\right]
$$

Though the correlation between $T_{\mathrm{BT}}$ and $I D$ is very good, until now no convincing explanation has been given for the physical meaning of the $I D$. Margolina and $\mathrm{Wu}^{9}$ and Sjoerdsma ${ }^{10}$ proposed a percolation model, but this was

*Current address: DSM Research, PO Box 18, 6160 MD Geleen, The Netherlands

$\dagger$ To whom correspondence should be addressed contradicted by Gaymans et al. ${ }^{11}$. Borggreve et al. ${ }^{12}$ have proposed a transition from plane strain to plane stress with decreasing interparticle distance. This, however, seems unlikely since the stress state in between two particles is determined by the ratio between particle size and $I D$, which is a constant for a given volume fraction.

In Figure 1 the $T_{\mathrm{BT}}$ is given as a function of the $I D$ for different rubber types. It appears that the critical interparticle distance $\left(I D_{\mathrm{c}}\right)$ depends on the rubber type. When the modulus of the rubber increases, $I D_{c}$ also increases ${ }^{4}$. A possible explanation for this behaviour is that not all the particles cavitate. In another paper ${ }^{13}$ it was demonstrated that the stress at which the rubber cavitates and the extent of cavitation also increase with increasing modulus of the rubber. This indicates that not only the distance between particles but the distance between cavitated particles is important for the transition from brittle to tough behaviour.

The level of the impact strength above and below $T_{\mathrm{BT}}$ appeared to be independent of particle size. Borggreve ${ }^{1}$ and $\mathrm{Wu}^{7}$ suggested that the impact strength in the tough region increased with increasing rubber content. Since the interparticle distance is a function of rubber volume fraction and rubber particle size, the impact strength is not directly dependent on the interparticle distance.

All the studies mentioned above were done under impact conditions, i.e. at high deformation rates (the strain rate is determined by the hammer velocity, which is $3.5 \mathrm{~m} \mathrm{~s}^{-1}$ at impact). There are very few studies reported in the literature concerning the effects of strain rate on the deformation and fracture behaviour of notched nylon/rubber samples.

Lazzeri ${ }^{14}$ performed slow bend tests and Charpy impact tests on notched nylon-6/EPR samples (rubber 


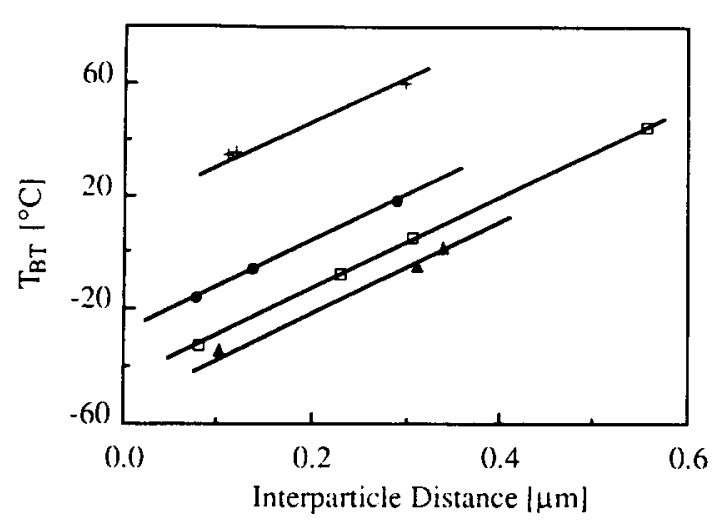

Figure 1 Plot of $T_{\mathrm{BT}}$ versus $I D$ for nylon-6/rubber blends with varying rubber concentration and particle size. Data taken from Borggreve $^{4}$ and Oostenbrink ${ }^{5}$, combined with unpublished data. Impact modifier: $(+)$ low-density polyethylene, LDPE; (O) ethylenepropylene rubber, EPR; ( $\square$ ) ethylene-propylene-diene monomer, $\operatorname{EPDM} ;(\boldsymbol{\Delta})$ butyl rubber, BR. ID calculated according to equation (1)

content $20 \mathrm{wt} \%$ ) and found that under slow bending the particle size hardly influenced the $T_{\mathbf{B T}}$ while under impact conditions the $T_{\mathrm{BT}}$ decreased linearly with particle size. It was suggested that the $I D$ does not have the same meaning at low and high deformation rates.

In order to get more insight into the impact behaviour of nylon/rubber blends, the fracture behaviour of notched nylon-6/EPR samples should be studied over a wide range of deformation rates. Bending tests like Charpy and Izod, however, impose a number of problems. To start with, when the fracture type is tough, the crack only propagates over two-thirds of the specimen. The Izod standard (ISO 180) requires complete fracture. There is then, especially at high speeds, the possibility of loss of contact between hammer and specimen (bouncing or multiple impact). Finally the stress state generated by the above-mentioned tests is quite complex, with tensile stresses at the notch and compressive stresses far away from the notch.

To overcome these problems another test method was developed, the notched tensile impact test (NTI test). Basically, the NTI test is a single edge-notched tensile test with the possibility of applying high deformation rates. With this test it is possible to vary the test speed over a broad range. The fracture will always be complete and the loading type will closely resemble a mode I fracture.

\section{EXPERIMENTAL}

\section{Materials}

The matrix material is a nylon-6 (type Akulon K124) obtained from Akzo; $\eta_{\text {rel }}$ in $96 \% \mathrm{H}_{2} \mathrm{SO}_{4}$ is $2.4, M_{\mathrm{n}}$ is $15000 \mathrm{~g} \mathrm{~mol}^{-1}$ and $\rho$ is $1.14 \mathrm{~g} \mathrm{ml}^{-1}$.

The impact modifier is a maleic anhydride (MA) modified ethylene-propylene $(75 / 25 \mathrm{wt} \%)$ copolymer (type Exxelor VA1801) kindly supplied by Exxon; the MA content is $0.7 \mathrm{wt} \%$ and $\rho$ is $0.89 \mathrm{~g} \mathrm{ml}^{-1}$.

\section{Blend preparation}

The blends were prepared in a two-step extrusion process. In the first step a $20 \mathrm{wt} \%$ master batch was prepared on a Berstorff ZE 25 co-rotating twin-screw extruder with a screw diameter of $25 \mathrm{~mm}$ and $L / D$ of 33 . The nylon and rubber were fed in the fifth zone using a supply rate of $2 \mathrm{~kg} \mathrm{~h}^{-1}$. The barrel temperature was $290^{\circ} \mathrm{C}$ and the screw speed $100 \mathrm{rev} \mathrm{min}^{-1}$.
In the second step the master batch was diluted to the desired rubber content on a Brabender $42 / 7$ twin-screw extruder with a barrel temperature of $290^{\circ} \mathrm{C}$, a screw speed of $50 \mathrm{rev} \mathrm{min}{ }^{-1}$ and a supply rate of $2 \mathrm{~kg} \mathrm{~h}^{-1}$. In this way blends with a rubber content of $5,10,15$ and $20 \mathrm{wt} \%$ were prepared.

The specimens (according to ISO 180/1A, $l \times w \times t=$ $72 \times 10 \times 4 \mathrm{~mm}^{3}$ ) were injection moulded on an Arburg Allrounder 221-55-250. The notch (notch tip radius= $0.25 \mathrm{~mm}$, depth $=2 \mathrm{~mm}$ ) was milled in the specimen. Before testing the specimens were dried at $110^{\circ} \mathrm{C}$ under vacuum for $18 \mathrm{~h}$. This type of specimen was used for the notched Izod impact test as well as for the notched tensile impact tests discussed in this paper.

\section{Characterization of the blend morphology}

In order to determine particle size, particle size distribution and particle distribution, a sample was taken out of an injection-moulded specimen. On this sample a smooth surface was prepared with a diamond knife on a CryoNova LKB 2285-050 microtome. The sample temperature during microtoming was $-110^{\circ} \mathrm{C}$.

From these samples the rubber was extracted from the surface by etching in boiling $m$-xylene for about $12 \mathrm{~h}$. After drying the samples at $110^{\circ} \mathrm{C}$ under vacuum for one night they were covered with a layer of gold and examined with a JEOL JSM-35CF scanning electron microscope. From the micrographs the particle size was determined.

\section{The notched tensile impact tests}

The high-speed tensile tests were carried out on a Schenck VHS servo-hydraulic tensile tester. With this apparatus it is possible to achieve a deformation speed of $12.5 \mathrm{~m} \mathrm{~s}^{-1}$. For the low-speed tests (up to $1 \mathrm{~mm} \mathrm{~s}^{-1}$ ) an Instron tensile tester was used. During the high-speed tests the data sampling was done by a transient recorder with a maximum sampling frequency of $2 \mathrm{MHz}$ per channel. The force was recorded with a piezoelectric force transducer. The displacement of the piston, as well as the displacement of the moving clamp, was recorded.

The VHS tensile tester is equipped with a special pick-up unit. With this unit, the piston can accelerate to the desired speed before loading the specimen. The initial contact between piston and pick-up unit is damped with a rubber pad in order to reduce harmonic oscillations in the specimen after impact ${ }^{15}$. The test set-up is given schematically in Figure 2.

In Figure 3 a typical example of a stress-displacement graph, as measured with the notched tensile impact test, is given for a tough fracturing sample. For each curve, the maximum stress was recorded and the energy supplied to the specimen during the test. The energy dissipation (the fracture energy) was calculated by integrating the force and displacement signals.

The fracture energy is divided into an initiation part and a propagation part. The point of maximum stress is chosen as the boundary between crack initiation and crack propagation. In the case of brittle behaviour, the stress falls almost instantaneously from the maximum stress to zero. Therefore, a brittle fracture will be characterized by a very low propagation energy.

Each test was carried out five times. In Table 1 typical values for the standard deviation of the recorded parameters are given. Since, for piston speeds above $1 \mathrm{~m} \mathrm{~s}^{-1}$, vibration of the specimen could not be prevented 


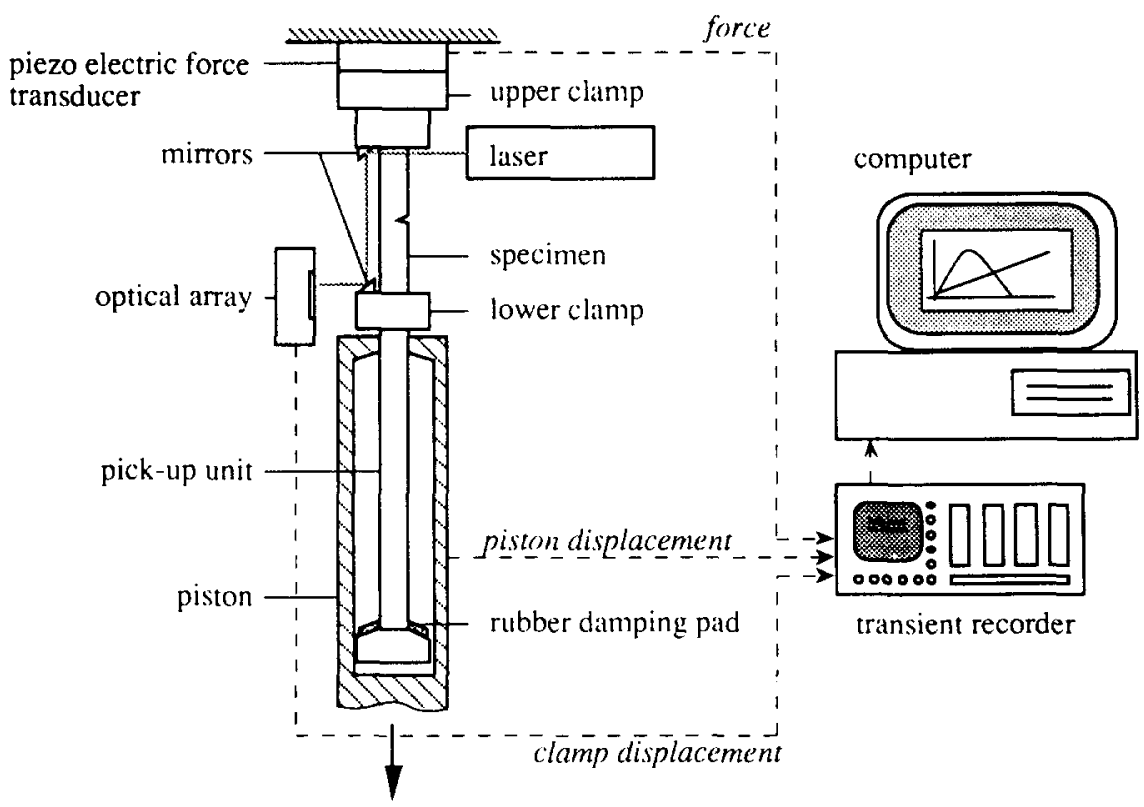

Figure 2 Test set-up for the notched tensile impact tests

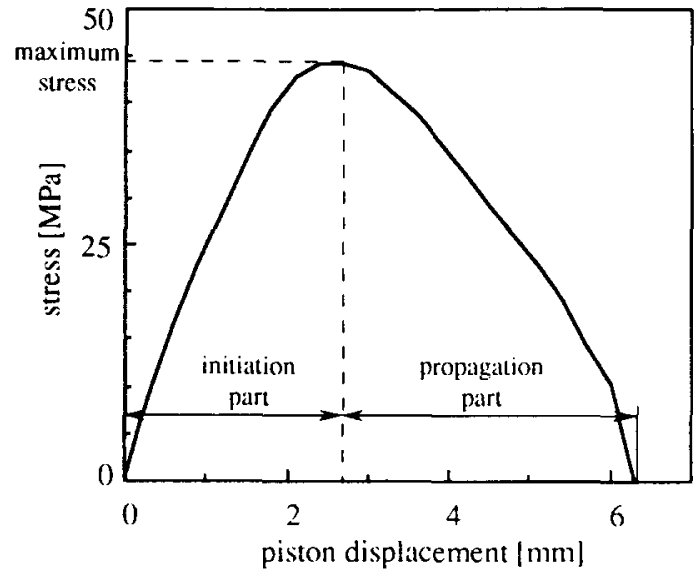

Figure 3 Typical stress-displacement curve, as measured with the NTI test, for a nylon-6/rubber blend, deformed with a low piston speed $\left(v=10^{-5} \mathrm{~m} \mathrm{~s}^{-1}\right)$. The material is the $20 \mathrm{wt} \%$ nylon-6/EPR blend given in Table 2

Table 1 Typical vaues for the standard deviation, as a percentage of the mean value, of the parameters measured in notched tensile impact tests (performed five times)

\begin{tabular}{lllll}
\hline & $\begin{array}{l}\text { Maximum } \\
\text { stress } \\
(\%)\end{array}$ & $\begin{array}{l}\text { Initiation } \\
\text { energy } \\
(\%)\end{array}$ & $\begin{array}{l}\text { Propagation } \\
\text { energy } \\
(\%)\end{array}$ & $\begin{array}{l}\text { Fracture } \\
\text { energy } \\
(\%)\end{array}$ \\
\hline$v \leqslant 1 \mathrm{~m} \mathrm{~s}^{-1}$ & 1 & 10 & 10 & 5 \\
$v>1 \mathrm{~m} \mathrm{~s}^{-1}$ & 5 & 15 & 15 & 10 \\
\hline
\end{tabular}

completely, a division is made between low- and intermediate-velocity $\left(v \leqslant 1 \mathrm{~m} \mathrm{~s}^{-1}\right)$ and high-velocity $\left(v>1 \mathrm{~m} \mathrm{~s}^{-1}\right)$ tests.

\section{RESULTS AND DISCUSSION}

\section{Blend morphology}

In Table 2 the number-average rubber particle size $d_{\mathrm{n}}$ and the weight-average particle size $d_{\mathrm{w}}$ of the prepared blends are given. The particle size is nearly the same for all the blends. The particle size distribution is in all cases relatively narrow, with values of $d_{\mathrm{w}} / d_{\mathrm{n}}$ smaller than 1.5 .
Table 2 Blend morphology of the prepared nylon-6/(MA-EPR) blends

\begin{tabular}{|c|c|c|c|c|c|c|}
\hline \multirow[b]{2}{*}{ Blend code } & \multicolumn{2}{|c|}{ Rubber content } & \multirow{2}{*}{$\begin{array}{l}d_{\mathrm{n}} \\
(\mu \mathrm{m})\end{array}$} & \multirow{2}{*}{$\begin{array}{l}d_{\mathrm{w}} \\
(\mu \mathrm{m})\end{array}$} & \multirow[b]{2}{*}{$d_{\mathrm{w}} / d_{\mathrm{n}}$} & \multirow{2}{*}{$\begin{array}{l}I D_{\mathrm{w}} \\
(\mu \mathrm{m})\end{array}$} \\
\hline & $(w t \%)$ & (vol\%) & & & & \\
\hline B05 & 5 & 6.3 & 0.28 & 0.41 & 1.46 & 0.42 \\
\hline B10 & 10 & 12.5 & 0.26 & 0.39 & 1.50 & 0.24 \\
\hline B15 & 15 & 18.4 & 0.25 & 0.36 & 1.44 & 0.15 \\
\hline B20 & 20 & 24.3 & 0.20 & 0.29 & 1.45 & 0.08 \\
\hline
\end{tabular}

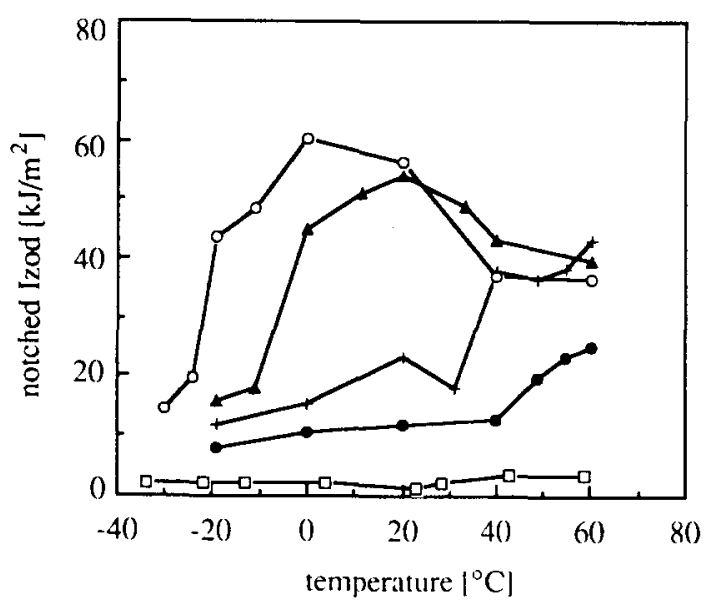

Figure 4 Notched Izod impact strength versus temperature for nylon-6/EPR blends with varying rubber content and constant rubber particle size. Rubber volume fraction: $(\square) 0.00,(0) 0.063,(+) 0.125$, $(\triangle) 0.184,(O) 0.243$. Information on the morphology of the blends tested is given in Table 2

The interparticle distance (ID), given in the last column, is calculated according to equation (1). No particle clusters could be observed on the micrographs.

\section{Notched Izod impact tests on nylon-6/EPR blends}

The results of the notched Izod impact tests on the prepared nylon-6/EPR blends are given in Figure 4. They are consistent with the results of Borggreve et al. ${ }^{1}$, where the brittle-to-tough transition temperature shifts to lower 
temperatures with increasing rubber content. The impact strength in the tough region shows the same decrease with temperature as reported by Oostenbrink ${ }^{5}$, despite the fact that the particle size is above the critical particle size of $0.2 \mu \mathrm{m}$ found by Oostenbrink. A possible explanation for this behaviour is that the blends tested here are less homogeneous. The reduced homogeneity can be caused by the dilution step on the Brabender extruder.

A striking feature of the results presented in Figure 4 is that the impact strength for the temperatures well above the $T_{\mathrm{BT}}$ appears to be independent of the rubber content. This was not reported in previous studies ${ }^{1,7}$. In fact, the data suggest that, at the highest test temperature, the impact strength even decreases slightly with increasing rubber content. This indicates that a high rubber content is necessary to shift the $T_{\mathrm{BT}}$ to low temperatures, but that it is not necessarily advantageous for a high impact strength in the region well above $T_{\mathbf{B T}}$.

\section{Deformation and fracture of nylon- 6}

In Figure 5 the results of the NTI tests on the homopolymer are given. As can be seen from the very low propagation energy in Figure $5 b$, the nylon breaks in a brittle fashion over the entire deformation speed range. The fracture energy, therefore, is completely dominated by the initiation phase.

In the low-speed region the stress-displacement curves are horizontal just before the point of fracture. This suggests that, despite the high triaxial tension ahead of
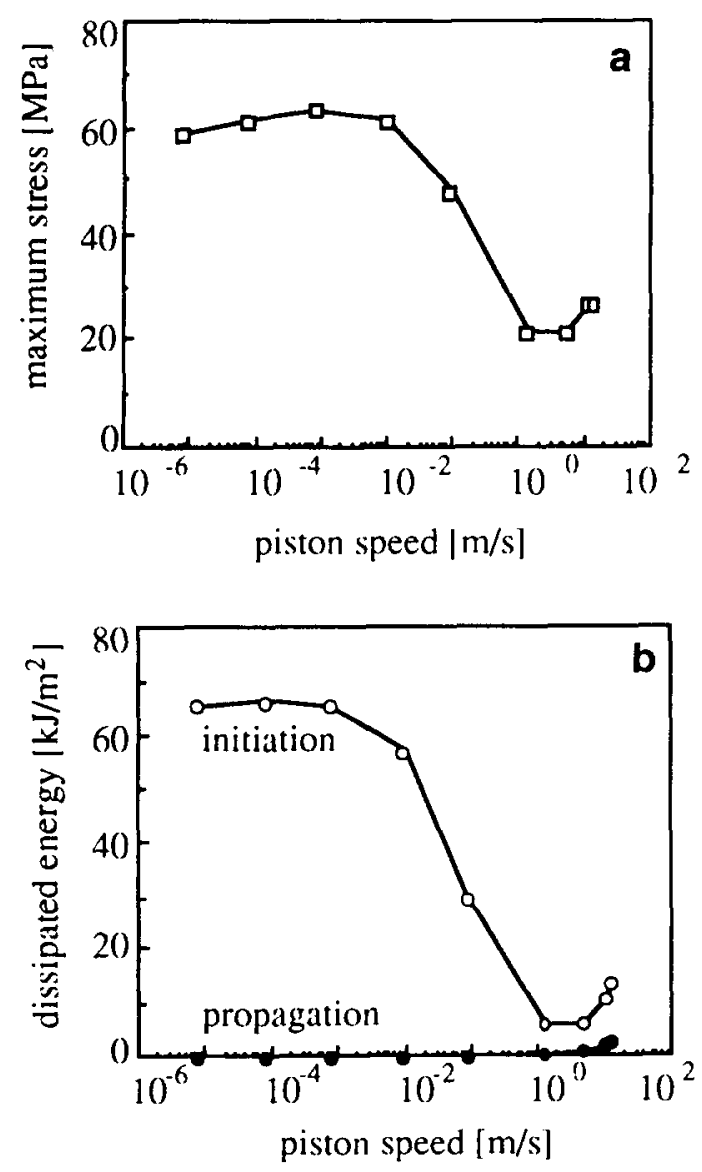

Figure 5 Results of the NTI tests on unmodified nylon-6 (Akulon K124): (a) maximum stress versus the piston velocity; (b) initiation and propagation energy versus piston velocity

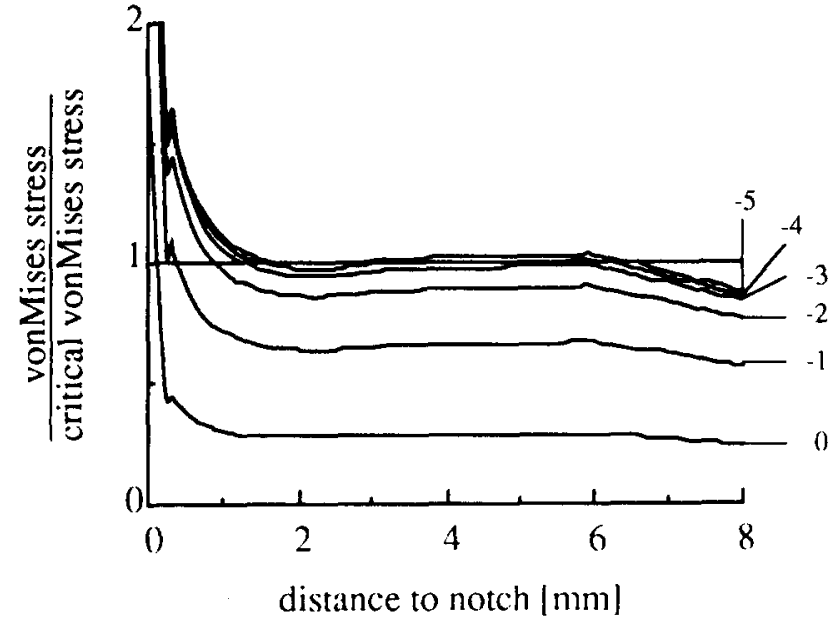

Figure 6 Relative von Mises stress versus the distance to the notch at the point of maximum stress in the NTI tests done on nylon-6. The numbers next to the curves represent the $\log$ (piston speed)

the notch, large-scale yielding has taken place over the whole cross-section ahead of the notch.

In order to evaluate the ability of the nylon specimens to undergo shear banding during an NTI test, the stress distribution in a notched specimen, subjected to a uniaxial stress far away from the notch, was determined, using a finite-element approximation. The specimen is assumed to be under plane strain. In this way the von Mises stress in the cross-section ahead of the notch as a function of the applied stress was calculated. Yielding is assumed to take place when the von Mises stress exceeds a critical value.

Data for the critical von Mises stress as a function of deformation rate for a similar material (Akulon K123H) were given by Bosma ${ }^{16}$. Combining these data (a correction is made to take into account the differences in strain rate due to different specimen geometries) with the maximum stress, measured in the NTI test (Figure 5a) and the finite-element calculations, Figure 6 is constructed, where the von Mises stress relative to the critical von Mises stress is given versus the distance to the notch for different piston speeds.

When the curves in Figure 6 are observed, it can be seen that the von Mises stress is maximum at the base of the notch, and decreases with increasing distance from the notch. The small peak at $0.5 \mathrm{~mm}$ and the kink at $6 \mathrm{~mm}$ in the curves are probably caused by inaccuracies in the numerical approximations.

Figure 6 shows that for the three lowest deformation rates the three upper curves are almost identical and yielding appears to be possible over almost the entire cross-section of the specimen. When yielding takes place over the entire cross-section, all the applied strain will be concentrated in the plastic zone. This means that at the point of massive yielding the local strain rate in the plastic zone will suddenly rise (e.g. with a size of the plastic zone of $500 \mu \mathrm{m}$ and a sample length of $5 \mathrm{~cm}$, the local strain rate will be two decades higher than the applied strain rate). This means that the point of gross yielding of the cross-section will practically coincide with the crack initiation point.

At higher speeds the region where shear banding is possible rapidly decreases in size. A sudden drop in the fracture energy as well as in the maximum stress is observed between a piston speed of 0.01 and $1 \mathrm{~m} \mathrm{~s}^{-1}$. 
The raw data show that the crack is initiated at lower strains in this speed range. Also the horizontal part in the stress-displacement curves is absent now.

Embrittlement of polymers with rising strain rate (or decreasing temperature) is a well known phenomenon ${ }^{17,18}$. Hashemi and Williams ${ }^{19}$ describe a similar transition from semi-brittle to brittle behaviour in rubber-toughened poly(vinyl chloride) (PVC) with decreasing temperature. They explained this behaviour from the fact that with decreasing temperature (i.e. with rising strain rate) the requirements for a plane-strain failure are met more and more.

As already mentioned, the crack propagation is in all cases brittle. The fracture surfaces of all specimens show signs of crack branching. Only the specimens tested at the highest strain rates (piston speed $\geqslant 1 \mathrm{~m} \mathrm{~s}^{-1}$ ) are very smooth and do not show crack branching. Also the maximum stress and crack initiation energy rises slightly in this region and the crack propagation energy becomes significantly higher than zero. The discussion of this different behaviour at high speeds is treated in the following part of this paper.

\section{DEFORMATION AND FRACTURE OF NYLON-6/EPR BLENDS}

\section{The low-deformation-rate region}

In Figure 7 the results of the NTI tests on the nylon-6/EPR blends (Table 2) are given. At low deformation rates the blends show supertough behaviour. Differences in fracture energy between the blends and the pure nylon originate partly from the initiation phase but are mainly caused by a very high energy dissipation during crack propagation in the blends. It is remarkable that already a small amount of rubber is capable of drastically changing the deformation mechanism. When in fact the blends are compared, the fracture energy decreases slightly with increasing rubber content (see Figure 7a).

When the fracture surfaces are observed, a large stress-whitened zone is visible. In contrast to the stresswhitened zone in impacted Izod samples, the shape of the stress-whitened zone is not not ellipsoidal but more triangular with a maximum depth of about $5 \mathrm{~mm}$ (Figure 8). It can also be seen that macroscopic necking has taken place. This necking is more pronounced with increasing distance from the notch.

\section{Intermediate deformation rates}

With increasing draw speed, there is a rapid decrease in the initiation and the propagation energy. For the 5 and $10 \mathrm{wt} \%$ blends this decrease leads eventually to brittle behaviour at draw speeds of 0.01 and $0.1 \mathrm{~m} \mathrm{~s}^{-1}$, respectively. In both cases, brittle fracture is accompanied by crack branching; stress-whitening can only be observed in the region just ahead of the notch. For the 15 and $20 \mathrm{wt} \%$ blends the propagation energy shows a minimum at a draw speed of $0.01 \mathrm{~m} \mathrm{~s}^{-1}$. These materials, however, still fracture in a tough manner, with stresswhitening over the entire fracture surface. This indicates that the strong decrease in fracture energy is of a different nature than the one observed in the unmodified nylon.

At the draw speed where the fracture energy of the blends reaches a minimum, the fracture energy of the blends and of the unmodified nylon is approximately the
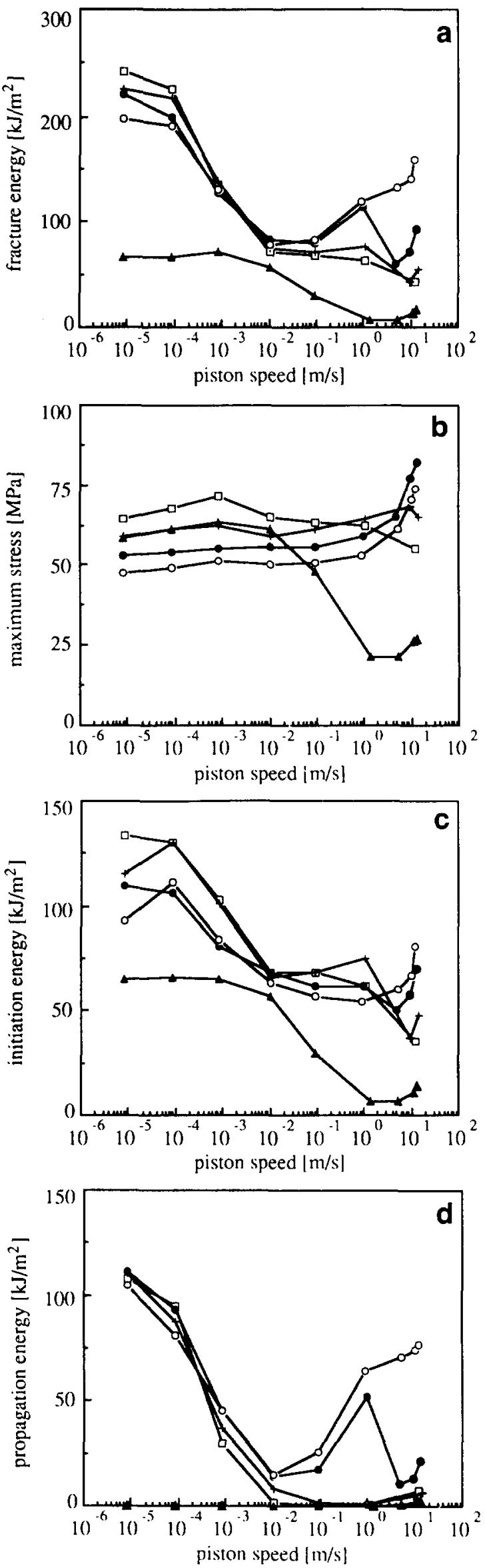

Figure 7 Results of the NTI tests on nylon-6/EPR blends with varying rubber content: (A) $0 \mathrm{wt} \%,(\square) 5 \mathrm{wt} \%,(+) 10 \mathrm{wt} \%$, (O) $15 \mathrm{wt} \%$, (O) $20 \mathrm{wt} \%$. The particle size is given in Table 2. (a) Fracture energy versus the piston speed; (b) maximum stress versus the piston speed; (c) initiation energy versus the piston speed; (d) propagation energy versus the piston speed 


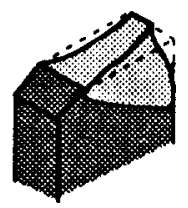

a

-.. undeformed geometry

stress-whitened region

Figure 8 Schematic representation of deformed NTI samples (20 wt $\%$ nylon-6/EPR): (a) piston speed $=10^{-5} \mathrm{~m} \mathrm{~s}^{-1}$; (b) piston speed $=10 \mathrm{~m} \mathrm{~s}^{-1}$

same for all the materials tested, despite the fact that at this speed both brittle and tough fracture is encountered. This leads to the conclusion that, in contrast with the notched Izod, it is not possible to discriminate between brittle and tough behaviour on the basis of the fracture energy alone. Brittle-to-tough transitions are, in the case of the NTI test, better observed in the propagation energy, which is approximately zero when the specimen fails in a brittle manner.

Despite the drop in fracture energy, the maximum stress remains fairly constant. Also the initiation energy remains fairly constant for all the blends in this region. Only when the fracture type changes from tough to brittle does the maximum stress tend to decrease. A strong decrease in maximum stress, as with the unmodified nylon, is not observed.

\section{High deformation rates}

In the high-speed region, the fracture energy of the 15 and the $20 \mathrm{wt} \%$ blends increases again. This is accompanied by a sudden increase in maximum stress. The $20 \mathrm{wt} \%$ blend keeps increasing up to the maximum applied strain rate and reaches a level close to that in the low-speed region. Also in this region the stresswhitened zone is more or less triangular in shape (Figure 8 ). The $15 \mathrm{wt} \%$ blend has a transition from tough to brittle between 1 and $5 \mathrm{~m} \mathrm{~s}^{-1}$.

The dependence of the fracture energy on the rubber content for the three different regions in the strain-rate regime (low, intermediate and high speed) is given in Figure 9. It is clear that only for the highest speeds is a higher rubber content beneficial for a high fracture energy. This is in agreement with the results of the notched Izod tests. For the low and intermediate draw speeds a low rubber concentration is already sufficient for toughening nylon. A high rubber content actually appears not to give an optimal fracture energy.

An important question is whether the brittle-to-tough transition temperature is affected by the way the specimen is loaded. Figure 4 shows that in the notched Izod impact test at room temperature the 0,5 and $10 \mathrm{wt} \%$ blends fracture in a brittle way, while the 15 and $20 \mathrm{wt} \%$ blends are tough. The initial deformation speed ahead of the notch of an Izod specimen is estimated to be $1 \mathrm{~m} \mathrm{~s}^{-1}$. The results of the NTI test (Figure $7 d$ ) with a draw speed of $1 \mathrm{~m} \mathrm{~s}^{-1}$ show indeed that the 0,5 and $10 \mathrm{wt} \%$ blends are brittle and the 15 and $20 \mathrm{wt} \%$ blends fail in a ductile manner. This indicates that the $T_{\mathrm{BT}}$ has not shifted to other temperatures.

\section{DISCUSSION}

The main difference between the blends and the pure nylon is that in the blends cavitation does not necessarily take place in the matrix but in the rubber particles. Since cavitation of the rubber starts at relatively low stresses, plastic deformation of the matrix will already be possible in an early stage of the deformation process and at a greater distance from the notch ${ }^{20}$. This plastic deformation can have two effects: first, an increase in the notch tip radius, with a consequent decrease of the stress concentration; secondly, a higher orientation in the matrix material. Both effects lead to a higher maximum stress and a higher energy dissipation during the initiation phase. The fact that the crack propagation is stable indicates that this mechanism is also operative during crack propagation.

As mentioned before, the fracture energy of the two blends with the highest rubber content starts to rise for draw speeds above $1 \mathrm{~cm} \mathrm{~s}^{-1}$. This is in contradiction with what might be expected since the yield stress keeps increasing in this region.

When the stress-strain curves recorded at intermediate rates are studied (Figure 10), it appears that during the

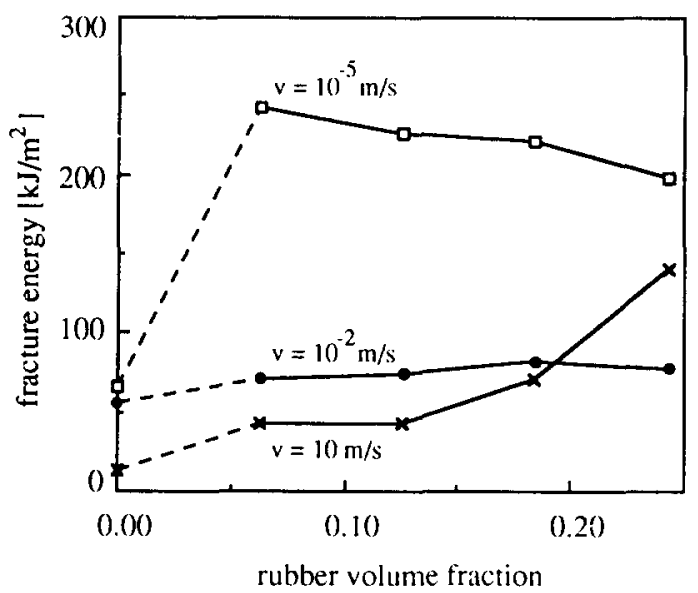

Figure 9 Fracture energy versus rubber concentration for three different piston speeds

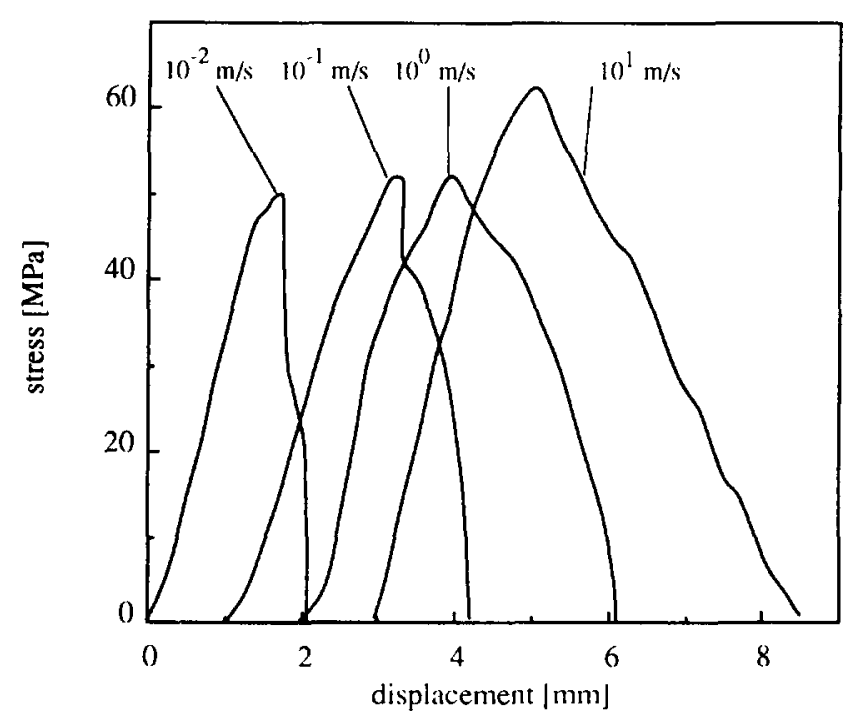

Figure 10 Stress-displacement curves for the $20 \mathrm{wt} \%$ nylon-6/EPR blend. The applied draw speed with which the curves were recorded is given in the figure 
initial part of the crack propagation there is a rapid decrease of the stress, which indicates a rapid crack growth. At a certain point, the crack becomes stabilized, which follows from the much slower decrease of the applied stress versus strain. With increasing strain rate, the drop in the stress after the crack has initiated becomes less pronounced and with a draw speed of $1 \mathrm{~m} \mathrm{~s}^{-1}$ it is hardly visible any more. Above this draw speed of $1 \mathrm{~m} \mathrm{~s}^{-1}$ the sudden increase in maximum stress is observed. This indicates that there is an extra deformation mechanism operative in the intermediate- and high-speed regime, which enables the crack propagation to become stabilized. At the highest speed the data even suggest that this mechanism becomes operative before the crack is initiated and is successful in postponing crack initiation, which results in a sudden increase in the maximum stress.

Oostenbrink et $a .^{21}$ showed that directly under the fracture surface of fractured Izod samples there is a layer where no cavitation or matrix deformation was visible. It was made plausible ${ }^{22}$ that this layer is a result of local melting caused by plastic deformation under adiabatic conditions. From model calculations it followed that the deformation rate and the size of the plastic zone were the parameters that determined whether the test was performed under isothermal or adiabatic conditions.

It was proposed by Williams and Crouch $^{23}$ that thermal crack tip blunting can play an important role in the toughening of thermoplastics, though the authors did not elaborate on the possibility that the thermal effects might be strong enough to exceed the melting point. The effect of thermal blunting can be made clear using Figure 11.

It is not clear at this moment whether the material melts in the region ahead of the crack tip or whether the melt zone interacts with the crack tip. In both cases there is a zone around the crack tip that does not bear any stresses. Therefore, from a mechanical point of view, the effective radius of the crack tip will in fact be the radius of the melt zone. From SEM micrographs ${ }^{22}$ it was concluded that the melt zone had a thickness of about $3-5 \mu \mathrm{m}$, which means that the radius of the melt zone is also about $3-5 \mu \mathrm{m}$. It was also calculated that with a draw speed of $10^{-4} \mathrm{~m} \mathrm{~s}^{-1}$ the test is performed under isothermal conditions while with a draw speed of $1 \mathrm{~m} \mathrm{~s}^{-1}$ the deformation is almost adiabatic.

For intermediate draw speeds, the test will be neither isothermal nor adiabatic. This means that at this moment the actual rise in temperature is still unknown. It may be possible that, when the crack is just initiated and the crack velocity is still low and/or the deformation zone small, the temperature rise will not be enough for the melt zone to be formed. During crack propagation, however, there may be a point where the melt zone is formed. This will possibly result in a stabilization of the crack. As the draw speed increases, the point where the local deformation rate becomes high enough to enable the formation of a melt layer, and thus the point where the crack is stabilized, is reached sooner.

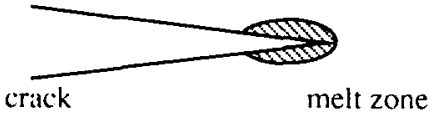

Figure 11 Schematic representation of the melt zone around a running crack
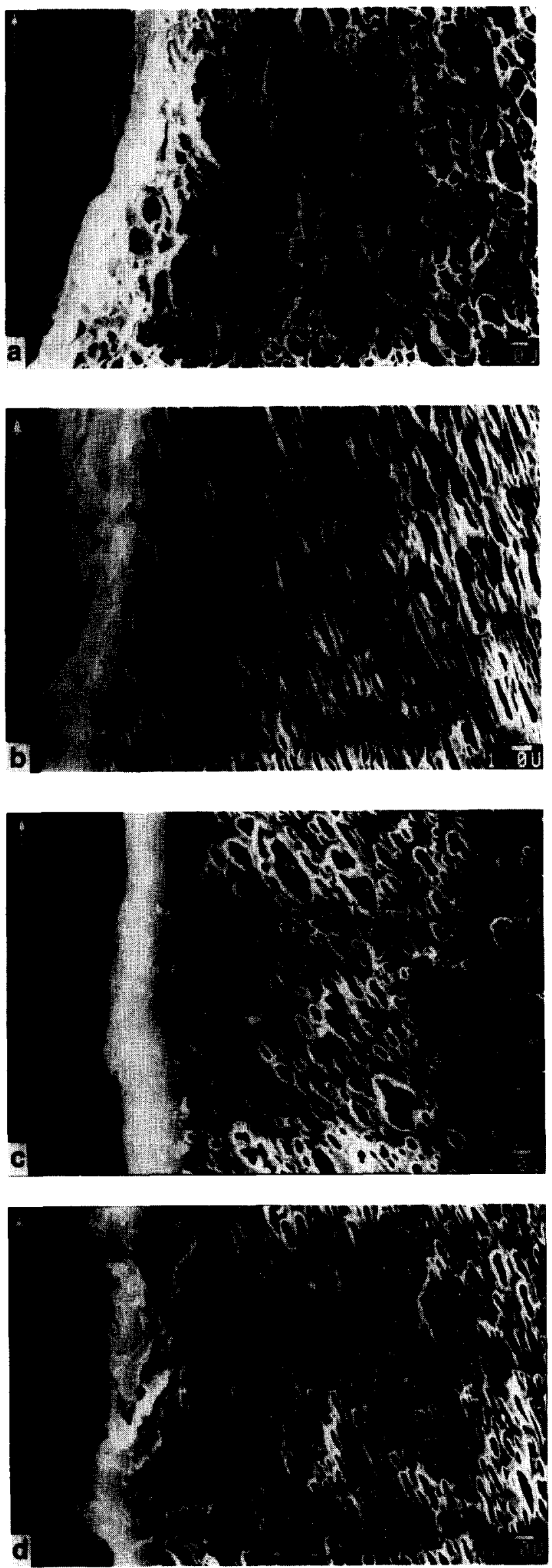

Figure 12 Deformation zones in nylon-6/EPR (20wt \%) NTI samples. Draw speed $0.01 \mathrm{~m} \mathrm{~s}^{-1}$ : (a) $1 \mathrm{~mm}$ ahead of the notch; (b) middle of the specimen. Draw speed $1 \mathrm{~m} \mathrm{~s}^{-1}$ : (c) $1 \mathrm{~mm}$ ahead of the notch; (d) middle of the specimen. The arrow indicates the direction of crack growth 
To check the mechanism described, SEM micrographs were obtained from the zone directly under the fracture surface just ahead of the notch and in the middle of the specimen (Figure 12). The method used for sample preparation was described in another paper ${ }^{22}$. Just ahead of the notch, the deformation zone of the sample fractured at intermediate draw speed shows a very coarse structure and there is no sign of a melt layer. When the same material is fractured under impact conditions, the melt zone is clearly visible. Though the plastic zone itself is still thin compared to the thickness of the plastic zone encountered in the middle of the specimen, the thickness of the melt zone is already about $3-5 \mu \mathrm{m}$. The micrographs taken in the middle of the specimens are very similar. In both cases directly under the crack plane a layer is visible with less deformation and cavitation than in the material further away from the crack.

\section{CONCLUSIONS}

With the notched tensile impact test it is possible to study the deformation and fracture behaviour of notched samples over a deformation-rate range that includes the strain rates applied in the normal tensile test and in impact tests like the notched Izod. A distinction can be made between the energy dissipation during the initiation phase and the propagation phase.

In the speed range tested the unmodified nylon has a transition from semi-brittle to brittle behaviour. When the nylon breaks in a semi-brittle manner, shear banding is possible over the entire cross-section before the crack is initiated. With brittle behaviour, yielding is only possible in a small region ahead of the notch. The unmodified nylon-6 has an unstable crack propagation for all the applied draw speeds.

When the applied deformation rate is low, already a very low rubber concentration is capable of toughening the nylon. With higher rubber concentrations there is a small decrease in fracture energy. This is consistent with the results of notched Izod impact tests at high temperatures. With increasing test speed there is a rapid decrease in fracture energy.

With intermediate draw speeds, the early part of the crack propagation is unstable. At a certain point, however, crack propagation can become stabilized. Owing to the unstable part in the propagation phase, the fracture energy is low despite the fact that the specimens have the appearance of tough fractured samples. When the draw speed is increased, crack stabilization takes place at an earlier point in the propagation phase. It is proposed that when the deformation is adiabatic a melt zone is formed around the running crack. By formation of a melt zone, the crack is effectively (thermally) blunted and crack propagation is stabilized.

In the high-speed region a sudden rise in the maximum stress and the initiation energy is observed. This is attributed to the fact that, owing to an adiabatic temperature rise of the material ahead of the notch, the notch tip also is blunted and crack initiation is postponed.

\section{ACKNOWLEDGEMENTS}

We would like to thank Prof. Dr. Ir. L. C. E. Struik for helpful discussions. This work is part of the research programme of the University of Twente and was financially supported by the SON/STW.

\section{REFERENCES}

1 Borggreve, R. J. M., Gaymans, R. J., Schuijer, J. and Ingen Housz, J. F. Polymer 1987, 28, 1489

2 Gaymans, R. J., Borggreve, R. J. M. and Spoelstra, A. B. J. Appl. Polym. Sci. 1989, 37, 479

3 Borggreve, R. J. M. and Gaymans, R. J. Polymer 1989, 30, 63

4 Borggreve, R. J. M., Gaymans, R. J. and Schuijer, J. Polymer $1989,30,71$

5 Oostenbrink, A. J., Molenaar, L. J. and Gaymans, R. J. PPF Polym. Process. Conf., Nice, 1990, Prep. P07-16

6 Oshinski, A. J., Keskulla, H. and Paul, D. R. Polymer 1992, 33, 268

Wu, S. Polymer 1985, 26, 1855

Wu, S. Polym. Prepr. 1987, 28, 179

Margolina, A. and Wu, S. Polymer 1988, 29, 2170

Sjoerdsma, S. D. Polym. Commun. 1989, 30, 106

Gaymans, R. J. and Dijkstra, K. Polymer 1990, 31, 971

Borggreve, R. J. M., Gaymans, R. J. and Eichenwald, H. M. Polymer 1989, 30, 78

13 Dijkstra, K., van der Wal, A. and Gaymans, R. J. J. Mater. Sci. submitted

14 Lazzeri, A., PhD Thesis, Cranfield Institute of Technology, UK, 1991

15 Béguelin, Ph., Barbezat, M. and Kausch, H. H. J. Physique III 1991, 1, 1867

16 Bosma, M., Poster presented at the Prague Meetings on Macromolecules, 1990

17 Ward, I. M. 'Mechanical Properties of Solid Polymers', 2nd Edn., Wiley, New York, 1983, p. 424

18 Vincent, P. I. Plastics 1961, 26, 141

19 Hashemi, S. and Williams, J. G. Polymer 1987, 27, 384

20 Dijkstra, K. and ten Bolscher, G. H. J. Mater. Sci. submitted

21 Oostenbrink, A. J., Dijkstra, K., van der Wal, A. and Gaymans, R. J. PRI Conf., Cambridge, 1990, Paper 50

22 Dijkstra, K. and Gaymans, R. J. J. Mater. Sci. submitted

23 Williams, J. G. and Crouch, B. A. PRI Conf., Cambridge, 1985, Paper 30 